\title{
Alterações Climáticas, Perceções e Racionalidades *
}

\section{Climate Change, Perceptions and Rationalities}

\author{
Vanda Viegas ${ }^{@, 1,2}$; Ulisses M. Azeiteiro ${ }^{1,2}$; João Alveirinho Dias ${ }^{3}$; Fátima Alves ${ }^{4,5}$
}

\begin{abstract}
RESUMO
Considerando que as Alterações Climáticas (AC) - uma das cinco áreas-guia da Estratégia 2020 da Comissão Europeia - são um problema global que requer respostas locais articuladas aos níveis macro, meso e micro; e que a sua compreensão implica a identificação das relações reciprocamente influentes entre a Natureza, a Sociedade e a Cultura; qualquer intervenção - seja no sentido da mitigação das $\mathrm{AC}$, seja no sentido da adaptação às $\mathrm{AC}$ - envolve necessariamente essa mesma sociedade, em toda a complexidade das suas dimensões socioculturais e ambientais. Neste artigo, enquadrado pelas teorias compreensivas, refletimos brevemente sobre algumas das inter-relações entre os sistemas climáticos, ambientais e socioculturais e defendemos que as racionalidades leigas, por se enraizarem em tipos e fontes de saber plurais, são um dos pilares para melhor se compreender e lidar com o fenómeno das AC.
\end{abstract}

Palavras-chave: racionalidades leigas, alterações climáticas, capital social, saberes-poderes, sustentabilidade

\begin{abstract}
Whereas Climate Change (CC) - one of the five prioritary areas of the Strategy 2020 of the European Commission - is a global challenge needing local responses, articulated at the macro, meso and micro levels; and while its understanding entails identifying mutually influential relationships between Nature, Society and Culture, any intervention - either to mitigate or adapt to CC-necessarily involves society itself, in the full complexity of its sociocultural and environmental dimensions. In a world in the midst of a major demographic transition, with a population expected to reach 9 billion by 2050, issues like sustainability, resource use, scarcity and sharing, have been interwoven in the international, regional and local arenas. This paper develops in the light of comprehensive theories. The methodological procedures are based upon desk research and all the work relies on the reflexive notion and today's ubiquitous complexity. The spirit of this pivotal approach is the interest in knowledge, curiosity for different dimensions of knowledge and how it is (re)produced, articulated and reflected in the relationships of the individual human being, with itself, with other human beings, with other living creatures and with the environment. This papers argues that the lay rationalities, because they take root in various types and sources of knowledge, are one of the pillars to better understand and deal with the phenomenon of CC. Part one of this paper makes a brief reference to ethical implications, preceded by a succinct analysis of the key dynamics and processes, which are considered responsible for the variability and climate change in a diachronic perspective. Part two discusses some of the sustainability issues, with a brief introduction to the pathways and strategies for mitigating and adapting to CC, which have been outlined and lie ahead, linking the global dimension to the local dimension, governments to markets and to civil society. Finally, focusing on lay
\end{abstract}

(a) Corresponding author

${ }^{1}$ Universidade Aberta, Departamento de Ciências e Tecnologia, Palácio Ceia, Rua da Escola Politécnica, 141 - 147, $1269-001$ Lisboa, Portugal. e-mail: <vnd.vgs@gmail.com>.

2 Centro de Ecologia Funcional, Universidade de Coimbra, Portugal. e-mail: <ulisses@uab.pt>

${ }^{3}$ CIMA - Centro de Investigação Marinha e Ambiental da Universidade do Algarve, Faro, Portugal. e-mail: <jdias@ualg.pt>

${ }^{4}$ Universidade Aberta, Departamento de Ciências Sociais e Gestão, Palácio Ceia, Rua da Escola Politécnica, 141 - 147, 1269-001 Lisboa, Portugal;

${ }^{5}$ Centro de Estudos das Migrações e das Relações Interculturais e Centro de Ecologia Funcional - Ecologia e Sociedade, Universidade de Coimbra e Universidade Aberta, Portugal. e-mail: <fatimaa@uab.pt>

* Submission: 26 NOV 2013; Peer review: 15 JAN 2014; Revised: 28 FEB 2014; Accepted: 26 JUL 2014; Available on-line: 16 SET 2014 
rationalities, a brief approach is sought regarding the issues of reflexivity, social capital and the 'knowledge-power' concept, keeping in mind that the study of the social reality, which is complex in nature, is always a (de)constructed exercise of dialectics between generalization and specialization.

Keywords: lay rationalities, climate change, social capital, knowledge-power, sustainability.

\section{Introdução}

Num mundo em plena transição demográfica, que se perspetiva que em 2050 venha a ter cerca de 9 mil milhões de seres humanos (UN, 2013), as questões da sustentabilidade, do uso, da escassez e da partilha de recursos entretecem-se pelas arenas mundiais, regionais e locais.

Este trabalho desenvolve-se à luz das teorias compreensivas (Weber, 2014), no sentido em que não procuramos explicar a causalidade da ação social dos agentes, nem buscar leis da regularidade do funcionamento social. Procuramos a compreensão dos sentidos da ação social (Guerra, 2006). Os procedimentos metodológicos baseiam-se na pesquisa documental e a todo o trabalho subjazem a noção reflexiva e a omnipresente complexidade hodierna. $\mathrm{O}$ ânimo desta abordagem de charneira é o interesse pelo conhecimento, a curiosidade pelas diferentes dimensões dos saberes e de como estes se (re)produzem, se articulam e se refletem nas relações do Humano, consigo próprio, com o Outro, com os Outros Seres e com o Ambiente.

No presente artigo, começamos, na primeira parte, por uma breve referência a implicações éticas, antecedida de uma aproximação às principais dinâmicas e processos considerados responsáveis pela variabilidade e pelas alterações climáticas.

$\mathrm{Na}$ segunda parte, abordaremos algumas das questões da sustentabilidade, fazendo uma breve introdução aos percursos e às estratégias de mitigação das alterações climáticas e de adaptação a essas mesmas alterações que têm vindo a ser traçados e que se perspetivam, interligando o global ao local, os governos aos mercados e à sociedade civil.

Finalmente, e com foco nas racionalidades leigas (e.g., Alves, 2011), buscaremos uma breve aproximação a questões da reflexividade, do capital social (e.g., Fukuyama, 1999) e dos saberes-poderes (Foucault, 1992), tendo em mente que o estudo de uma realidade social, intrinsecamente complexa, é um exercício, sempre (des)construído, de dialética entre generalização e especialização.

\section{Da Variabilidade Climática}

\subsection{Das Dinâmicas Naturais}

O conhecimento científico atual permite saber, embora com as incertezas inerentes à Ciência, como é que a Terra se formou e como evoluiu ao longo de alguns milhares de milhões de anos, até adquirir as características que hoje a tipificam. Há, principalmente duas características que, tanto quanto sabemos, tornam a Terra única no contexto do sistema solar e, porventura, do galáxico ou, mesmo, do cósmico: água abundante no estado líquido e vida diversificada. Acredita-se que o desenvolvimento da vida só foi possível devido à existência de água no estado líquido, pelo que se pode concluir que o principal elemento diferenciador do planeta Terra é a água. Aproximadamente $71 \%$ da superfície terrestre está coberta de água, o que, vista do espaço, lhe confere uma tonalidade geral azulada, razão por que, com frequência, é apelidada de "Planeta Azul".

É muito provável que existisse uma quantidade apreciável de água no material que formou a Terra (e.g., Morbidelli et al., 2000; Drake, 2005), há pouco mais de 4,5 mil milhões de anos (Ma) (e.g., Nisbet \& Sleep, 2001). Possivelmente, a água líquida ocorria já à superfície uns $50 \mathrm{Ma}$ após as fases principais de acreção construtiva da Terra (Pinti, 2005), sendo provável que a intensa condensação do vapor de água atmosférico tenha produzido fortíssimas precipitações, da ordem de $7000 \mathrm{~mm} / \mathrm{ano}$, o que conduziu à formação muito rápida (talvez menos de um milhar de anos) dos oceanos (Abe, 1993). Todavia, até há cerca de 4 mil Ma, impactos meteoríticos ocasionais provocavam aquecimento dos oceanos então existentes, esterilizando-os (Nisbet \& Sleep, 2001). As mais antigas rochas sedimentares marinhas encontradas até agora (e que, portanto, conseguiram sobreviver aos intensos episódios tectónicos e metamórficos por que passaram) são as de Akilia, na Groenlândia Ocidental, datada de há uns 3,86 mil Ma (Nutman et al., 1996), e de Isua, no Sudoeste da Groenlândia, com 3,7 mil Ma (Rosing et al., 1996).

Embora se considere que a vida na Terra existe desde antes de 3,8 mil Ma (e.g., Nisbet \& Sleep, 2001; Schidlowski, 1988), a escassa biosfera então existente seria constituída por extremófilos, possivelmente hipertermófilos (e.g., Schidlowski, 1988; Rothschild \& Mancinelli, 2001), que talvez vivessem junto a exsudações hidrotermais oceânicas e que, por vezes, seriam destruídos devido a impactos meteoríticos. Os primeiros indícios seguros existentes indicam que, há 3,5 mil milhões de anos, a vida era já relativamente comum no planeta Terra (e.g., Nisbet \& Sleep, 2001; Schopf, 2006; Schopf et al., 2007; Lyons et al., 2014), ou seja, pode considerar-se essa a idade da biosfera terrestre (ainda que, na altura, fosse constituída apenas por organismos rudimentares). 
Os organismos fotossintéticos surgiram há mais de 2,8 mil Ma (e.g., Des Marais, 2000). Porém, a grande maioria do oxigénio libertado para a atmosfera pela fotossíntese era consumido pela oxidação de materiais, designadamente o ferro. Por isso, as formações com camadas vermelhas, devido à presença de ferro oxidado, são características desta época. Com a passagem do tempo e o aumento da libertação de oxigénio para a atmosfera pelos organismos fotossintéticos, a quantidade de oxigénio livre ampliou-se bastante, excedendo, a certa altura, a capacidade de absorção por materiais em estado reduzido. Há cerca de 2,3 mil Ma verificou-se um expressivo aumento de oxigénio atmosférico, evento esse que normalmente é conhecido pela designação de primeiro GOE (Great Oxidation Event ou Grande Evento de Oxigenação) (e.g., Falkowski, 2006; Guo et al., 2009; Crowe et al., 2013), passando a atmosfera a ter características oxidantes. Possivelmente, nesta produção intensa de oxigénio estiveram já envolvidos organismos eucariotas complexos (Nisbet \& Sleep, 2001). A formação de uma atmosfera oxigenada foi catastrófica para a maior parte dos organismos então existentes, anaeróbicos, para os quais o oxigénio era letal. Em compensação, começaram a surgir os organismos aeróbicos, que acabariam por evoluir para a vida tal como a conhecemos.

À medida que as moléculas de oxigénio foram atingindo níveis mais elevados da atmosfera, foi-se progressivamente criando uma fina camada enriquecida em ozono. Com efeito, na estratosfera, a energia da radiação ultravioleta (UV) do Sol cinde as moléculas de oxigénio $\left(\mathrm{O}_{2}\right)$ em átomos individuais $(\mathrm{O})$, que, combinando-se com outras moléculas de oxigénio, formam moléculas de ozono $\left(\mathrm{O}_{3}\right)$, muito eficazes na absorção de UV, constituindo-se, assim, uma fina camada que funciona como escudo, protegendo o planeta desta radiação, com comprimentos de onda de 200 a 300 nanómetros $(\mathrm{nm})$ e que é biologicamente letal. A construção progressiva desta camada protetora de ozono, a partir de há uns 2 mil Ma (e.g., Glikson, 2014; Maruyamab et al., 2014) ou mesmo antes, talvez há cerca de 2,6 Ma (Watanabe et al., 2000; Cockell \& Raven, 2007), juntamente com o enriquecimento da atmosfera em oxigénio, permitiu que as formas de vida migrassem até às camadas superficiais do oceano, viabilizando a proliferação do fitoplâncton, sendo mesmo possível que, nessa altura, tivessem ocorrido as primeiras tentativas de colonização de áreas emersas (Cockell \& Raven, 2007).

Há cerca de mil Ma ocorreu outro GOE, normalmente conhecido por Evento Neoproterozoico de Oxigenação (e.g., Ward et al., 2006; Shields-Zhou \& Och, 2010), que, progressivamente, criou condições para que, mais tarde, com início há cerca de $600 \mathrm{Ma}$, se verificasse o aparecimento de forma complexas de vida, cuja "explosão" se verificou no Câmbrico, há cerca de 541 (e.g., Marshall, 2006; Butterfield, 2007; BaudouinCornu \& Thomas, 2007). Depois dessa altura, o oxigénio atmosférico continuou a ser um fator determinante na progressiva adaptação da vida, nomeadamente dos artrópodes e vertebrados, aos ambientes terrestres (e.g., Ward et al., 2006; Baudouin-Cornu \& Thomas, 2007).

Após o Câmbrico, a composição da atmosfera nunca mais sofreu variações extremas, embora as quantidades relativas dos seus componentes tenham conhecido variações notáveis em função de um conjunto complexo de fatores, entre os quais, as glaciações, a geometria dos continentes, as erupções vulcânicas, as áreas cobertas por vegetação e os impactos meteoríticos. Por exemplo, o oxigénio variou, desde há $300 \mathrm{Ma}$ até à actualidade, entre cerca de $30 \%$ e de $11 \%$, sendo actualmente de $21 \%$, e o anidrido carbónico $\left(\mathrm{CO}_{2}\right)$ entre umas 300 ppm (partes por milhão) e cerca de 4000 ppm, sendo atualmente 397 ppm (e.g., Dudley, 1998; Ghosha et al., 2001; Came et al., 2006). Possivelmente, estas variações no conteúdo atmosférico em oxigénio foram determinantes nas vicissitudes por que a vida passou na longa história da Terra. Por exemplo, a ocupação relevante de ambientes terrestres parece ter ocorrido apenas quando a percentagem de $\mathrm{O}_{2}$ na atmosfera se começou a aproximar dos $20 \%$ (percentagem um pouco inferior à actual), há uns $440 \mathrm{Ma}$; a diversificação das formas de vida esteve, aparentemente, relacionada com os níveis elevados de $\mathrm{O}_{2}$ (chegando talvez a atingir mais de 25\%) que ocorreram entre 435 e $400 \mathrm{Ma}$; a subsequente diminuição dos níveis de oxigénio que se verificou entre 400 e $380 \mathrm{Ma}$, quando desceu a um mínimo inferior a $14 \%$, e se prolongou, com valores baixos, até há $345 \mathrm{Ma}$, esteve relacionada com a extinção, no Devónico superior, de muitas espécies terrestres (nomeadamente de artrópodes) e marinhas, pois o próprio oceano parece ter sofrido períodos de anoxia; o posterior acréscimo da percentagem de $\mathrm{O}_{2}$, que ultrapassou o nível actual de $21 \%$ há uns $335 \mathrm{Ma}$ e viria a atingir o máximo de $30 \%$ ou mais há uns 300 Ma, reflectiu-se, entre outras, na diversificação dos artrópodes terrestres e dos vertebrados, no aparecimento de novos taxa e na grande expansão das espécies vegetais subaéreas (Ward et al., 2006).

Se a composição da atmosfera é crucial para a evolução climática, essa evolução é, em muito, definida por causas astronómicas, nomeadamente pelos forçamentos orbitais, ou seja, pelos diferentes movimentos da Terra, principalmente a excentricidade da órbita, a obliquidade do eixo de rotação e a precessão dos equinócios, cuja ciclicidade é, em geral, conhecida pela designação de parâmetros de Milankovitch. A conjugação destes diferentes movimentos faz com que a Terra tenha maior ou menor insolação, o que, como é evidente, é um forçador climático básico. Por exemplo, 
os períodos glaciários e interglaciários são, em muito, definidos por estes parâmetros de Milankovitch.

Todavia, o sistema climático terrestre é muito complexo e ainda bastante mal conhecido. O sistema atmosferaoceano desempenha, também, um papel fundamental na evolução climática da Terra, em geral amortecendo os efeitos das variações rápidas (e.g., Bijma et al., 2013) mas, também, por vezes, suscitando modificações aceleradas, como aconteceu no Dryas Recente. Após um longo período glacial, a Terra estava já num estádio avançado de aquecimento, transicional para um período interglaciário, quando, há 12800 anos AP (antes do Presente), essa tendência se inverteu abruptamente, regressando a condições glaciais durante uns mil e trezentos anos. Segundo parece, o aquecimento climático provocou a progressiva fusão dos mantos de gelo da América do Norte; a introdução rápida desta água doce na parte setentrional do Atlântico fez com que esta, menos densa, se distribuísse à superfície (e.g., Johnson \& McClure, 1976; Broecker, 2006). Como o ponto de congelação da água doce $\left(0^{\circ} \mathrm{C}\right)$ é significativamente mais elevado do que o da água salgada $\left(-4^{\circ} \mathrm{C}\right)$, a superfície oceânica, a latitudes elevadas, teria congelado mais facilmente, interrompendo ou, pelo menos, reduzindo substancialmente a produção de Água Norte-Atlântica de Fundo (NADW) (e.g., Johnson \& McClure, 1976; Ganopolski \& Rahmstorf, 2001; Broecker, 2006). Refira-se que, com a atual configuração dos continentes, a produção de NADW é uma das peças essenciais do funcionamento climático da Terra. A circulação termo-halina faz com que haja, a níveis intermédios e subsuperficiais do Atlântico Norte, um movimento advectivo de água quente e salina das baixas para as altas latitudes. A estas latitudes, como junto à Islândia, esta água aflora à superfície e arrefece, ou seja, liberta calor, razão por que as regiões nordeste atlânticas não são tão frias como seriam se este processo não existisse. Isto significa que a água se torna mais densa e mergulha em direção ao fundo, gerando a NADW (e.g., Broecker, 1991; Kuhlbrodt et al., 2007), a qual vai influenciar o clima em todo o resto da Terra. Tendo, há 12800 anos AP, o Atlântico congelado a estas latitudes, a produção de NADW reduziu-se substancialmente, o que significa que o transporte de calor das baixas para as altas latitudes foi bastante amortecido; com a forte diminuição da circulação de água profunda, a deterioração climática acabou por se fazer sentir em toda a Terra. Acresce que, estando o mar gelado, o albedo se ampliou, fazendo com que, nessas regiões, a absorção da radiação solar diminuísse substancialmente, deteriorando ainda mais as condições climáticas. Processos de retroalimentação (feedback) como este, em que o arrefecimento provocou mais arrefecimento, ocorrem com relativa frequência no funcionamento do sistema climático. O curto período glaciar assim induzido acabaria por terminar há $11400 \mathrm{AP}$, evoluindo então o clima, definitivamente, para condições interglaciais persistentes.

Como a investigação científica opera nas fronteiras entre o conhecido e o desconhecido, raramente há certezas absolutas e, por via de regra, o progresso faz-se através de muitas dúvidas, de elaborações conjecturais e da formulação de hipóteses múltiplas. Tal é ainda mais relevante quando os assuntos estudados se caracterizam por elevada complexidade, como é o caso do sistema climático terrestre. Em contraposição à hipótese sucintamente apresentada acima, em que o Dryas Recente teria sido induzido pela fusão dos gelos e pelo amortecimento da produção de NADW, alguns investigadores defendem que o acontecimento que esteve na origem desse curto período glaciário foi uma explosão meteorítica na baixa atmosfera, pois que há indícios de que tal se verificou há 12900 anos (e.g., Firestone et al., 2007; Melott et al., 2010). As duas hipóteses não são incompatíveis e é bem possível que ambas se tenham potenciado para induzir a grande rapidez com que o Dryas Recente se instalou.

A dinâmica climática é pois afetada por uma miríade de variáveis, cujo comportamento químico e físico, interdependências mutuamente influentes, consequências e previsões, na sua globalidade, estão ainda por conhecer na totalidade.

\subsection{Da Ação Antrópica e Alterações Climáticas}

A United Nations Framework Convention on Climate Change (UNFCCC) considera como Alterações Climáticas apenas as mudanças resultantes direta ou indiretamente da atividade antrópica: ""Alteração climática" significa uma mudança de clima que é atribuída direta ou indiretamente à atividade humana que altera a composição da atmosfera mundial e que se soma à variabilidade climática natural observada ao longo de períodos comparáveis" (UNFCCC, 1998).

Neste trabalho, fundamentando com a interinfluência e a dinâmica dos componentes e processos naturais do sistema climático, seguimos a posição de Le Treut et al. (2007): “As alterações climáticas referem-se a uma mudança no estado do clima, que pode ser identificada (e.g., por meio de testes estatísticos) por mudanças na média e/ou na variação das suas propriedades e que persiste durante um longo período de tempo, tipicamente de décadas ou mais. A mudança climática pode ser devida a processos internos naturais ou a forçamentos externos, ou a mudanças antropogénicas persistentes na composição da atmosfera ou no uso da terra" (Le Treut et al., 2007).

Nesta pesquisa evidencia-se que as $\mathrm{AC}$ derivam não apenas dos impactes resultantes direta ou indiretamente da ação antrópica continuada, mas também, e em dinâmicas interinfluentes, das mudanças que resultam 
dos processos internos naturais do sistema climático ou do seu forçamento externo.

A capacidade de regeneração da natureza encontra-se comprometida na atualidade, nomeadamente alguns fenómenos que seriam passíveis de reabsorção e/ou regeneração/ autorregeneração natural (e.g., decomposição ou queima da biomassa, variabilidade vulcânica, etc.). A situação atual reflete pois, para além dos processos geológicos, os processos históricos, longos e demorados, que ao longo dos séculos têm vindo a gerar impactos, em particular a partir do Séc. XVIII, com a Revolução Industrial, mas sobretudo a partir da $2^{\mathrm{a}}$ Guerra Mundial e em crescendo até aos nossos dias.

Embora quase não tenha sido considerada até à década de 60 do Séc. XX, a explosão demográfica, em conjunto com as alterações do uso do solo e do modo de vida, particularmente o dos países afluentes, para além de contribuir largamente para a determinação dos atuais elevados índices de devastação ambiental e para uma ininterrupta fragmentação de ecossistemas (fragmentação de habitats), é ainda amplamente responsável, em resultado da própria ação antrópica, pelo forte aumento continuado dos gases de efeito de estufa (GEE) e dos aerossóis na atmosfera.

O IPCC defende: "Mudanças na quantidade atmosférica de GEE e aerossóis, na radiação solar e nas propriedades da superfície terrestre alteram o equilíbrio energético do sistema climático. Estas mudanças são expressas em termos de forçamento radiativo, que é usado para comparar como uma série de influências humanas e fatores naturais levam ao aquecimento ou ao arrefecimento do clima global"(IPCC, 2007).

Fenómenos como o da acidificação dos oceanos (Fabry et al., 2008) ou o da acidificação dos solos (Jones et al., 2012), exponenciados pela ação antrópica, estão estreitamente ligados com as Alterações Climáticas. Outro fenómeno agravado pela poluição, também com graves consequências aos níveis do equilíbrio dos ecossistemas, da economia e da saúde para os próprios humanos, é o fenómeno das chuvas ácidas (Monteith et al., 2007). De origem natural ou antropogénica, os efeitos secundários dos aerossóis, no entanto, podem levar a um forçamento radiativo do sistema climático (Ramanathan et al., 2001).

Conquanto não possa ainda ser provada a relação causa-efeito entre a emissão de GEE das atividades antrópicas poluentes e o aumento da temperatura, alguns modelos climáticos, em finais da década de 90 , considerando as interações do ciclo do carbono com o ciclo da água, já apontavam para alterações no ciclo hidrológico com efeitos, na sua globalidade, não totalmente previsíveis na evolução do clima na Terra (Sellers et al., 1997).

Segundo Houghton et al. (1996): “As concentrações atmosféricas de gases com efeito de estufa, inter alia, dióxido de carbono $\left(\mathrm{CO}_{2}\right)$, metano $\left(\mathrm{CH}_{4}\right)$ e óxidos de azoto $\left(\mathrm{NO}_{\mathrm{x}}\right)$ tiveram um aumento significativo. [...] Muitos permanecem na atmosfera por um longo tempo (caso do $\mathrm{CO}_{2}$ e $\mathrm{N}_{2} \mathrm{O}$, por muitas décadas e séculos), daí afetarem o forçamento radiativo em escalas de longo prazo" (Houghton et al., 1996).

As mudanças climáticas resultam, assim, de efeitos de dominó pelo encadeamento de processos, alguns dos quais irreversíveis, e com dinâmicas de longo tempo de resposta ou por inércia, no seu conjunto.

A miríade de tensões e de interações retroativas, naturais e antropogénicas contidas nos fenómenos das Alterações Climáticas, consubstanciada no aumento da temperatura, relaciona-se com a alteração da precipitação, com o aumento do nível do mar e com os cada vez mais presentes Eventos Extremos (IPCC, 2007).

No entanto, não é sem polémica entre a comunidade científica que se vai desenvolvendo a investigação sobre as AC, suas dinâmicas e evoluções. Um bom exemplo disso terá sido a carta aberta enviada em finais de 2012 ao Secretário-geral das Nações Unidas, Ban Ki-Moon, (Open letter to UN Secretary-General ${ }^{1}$ ) em que 125 cientistas que defendem não haver evidência científica de que a produção de $\mathrm{CO}_{2}$ tenha sido ou venha a ser responsável pelo aquecimento global observado.

\subsubsection{Sobre Ecossistemas, Serviços de Ecossistema,} Biodiversidade e Bem-estar

Nesta análise, e interligando com as questões ambientais e das AC, importa manter presente os efeitos que advêm da pressão exercida pelos ritmos e escala impostos, particularmente nos últimos 50 anos, pela atividade antrópica sobre a biodiversidade e, naturalmente, sobre a totalidade de ecossistemas que a compõem e de que o ser humano é parte integrante.

Sendo o ser humano parte dos ecossistemas, o seu bemestar, subjetiva e contextualmente percecionado e experienciado, é reflexo da interligação da conjuntura ecológica sociocultural local. O Millennium Ecosystem Assessment, em "Ecosystems and Human well-being $A$ Framework for Assessment" (MA, 2003), entende o bem-estar humano como o oposto em um continuum de pobreza - ambos conceitos plurais complexos, cuja análise e implicações não cabem no âmbito do presente artigo.

De acordo com o Relatório "Ecosystems and Human well-being Synthesis" (MA, 2005), um ecossistema refere-se a uma complexa e dinâmica unidade funcional, independentemente do tamanho, entre plantas, animais e microrganismos, em um determinado

\footnotetext{
1 Disponível on-line em http://opinion.financialpost.com/2012/11/ 29/open-climate-letter-to-un-secretary-general-current-scientificknowledge-does-not-substantiate-ban-ki-moon-assertions-onweather-and-climate-say-125-scientists/
} 
meio abiótico, cujos serviços são fundamentais para o bem-estar humano.

O MA (2005) enquadra os serviços dos ecossistemas, percebidos como benefícios, em quatro áreas:

a) Produção - e.g. água potável, alimentos, recursos genéticos...;

b) Regulação - e.g. clima, qualidade do ar, água, doenças humanas...;

c) Culturais - e.g. espirituais, religiosos, reflexão, lazer...;

d) Suporte - e.g. produção primária, oxigénio, formação do solo...;

Interligando as Alterações Climáticas, com a destruição, fragmentação e/ou alteração de habitats, com a invasão de espécies exóticas e com os efeitos antropogénicos, o sobreuso dos serviços dos ecossistemas, embora estes fatores tenham contribuído para aparentes (mas controversos e discutíveis) ganhos no desenvolvimento económico das gerações humanas atuais, levantam sérias preocupações relativamente à sustentabilidade da biodiversidade e, consequentemente, à sustentabilidade das gerações futuras, humanas e não-humanas (MA, 2005).

A complexidade, multiplicidade e quantidade de interações das dimensões climáticas, humanas e do ambiente, em processos mutuamente influentes $\mathrm{e}$ retroativos, têm consequências reconhecidamente devastadoras (Stocker et al., 2013), mas ainda de difícil quantificação.

Assim, e levando em consideração a incerteza, a caducidade do conhecimento e o desconhecimento cabal sobre as interações e a globalidade das intra- e das interdependências dos sistemas da Terra e dos sistemas humanos, verifica-se, entre outros, um aparente aumento de fenómenos a que se convencionou chamar de eventos extremos.

\subsection{Das Alterações Climáticas e das Implicações Éticas}

A amplitude das questões relacionadas com as Alterações Climáticas extravasa em muito, conforme referido, o campo meramente científico, pois relaciona-se profundamente com estratégias de poder e crescimento económico descontrolado, bem como com a perceção, a atitude e os comportamentos de risco antrópicos.

No entanto, uma consciencialização crescente da necessidade de proteção do ambiente foi ganhando peso e levou, entre outros, à adoção do 'Princípio da Precaução', o $15^{\circ}$ Princípio, na Declaração da RIO 92: "A fim de proteger o ambiente, o Princípio da Precaução deve ser amplamente observado pelos Estados, de acordo com suas capacidades. Quando houver ameaça de danos sérios ou irreversíveis, a falta de plena certeza científica não deve ser utilizada como razão para postergar medidas eficazes e economicamente viáveis para prevenir a degradação ambiental" (UNDESA, 1992).

Como a literatura confirma, a Ética é um conceito complexo e de recorte pouco definido, cujo âmbito se situa no domínio do normativo e do dever ser, i.e., no domínio dos valores (Lourenço, 2002). Lato sensu, a Ética liga-se à reflexão teórica e filosófica sobre o bem e o mal e sobre os grandes princípios - como os da justiça, do bem comum, da benevolência, do eudaimonismo (Aristóteles, 2009), da responsabilidade (Jonas, [1979] 1984), entre outros - os quais regulam e orientam atitudes, racionalidades e comportamentos nas nossas relações morais connosco e com os outros, seja de indivíduos ou de grupos humanos: comunidades, organizações, Estados, etc.

Com este enquadramento, poder-se-á definir a Ética Ambiental como a disciplina filosófica que reflete sobre as relações morais dos seres humanos, estendendo as questões da moralidade às relações dos humanos com a Natureza, com os ecossistemas e com os outros seres vivos não humanos.

Assim considerada, a Ética Ambiental entende-se como o esteio, de referências e valores, orientador e normalizador da conduta e ação humanas não apenas relativamente aos humanos, mas também ao Ambiente, à sua preservação e conservação.

De acordo com Shue (2005), a maior parte da reflexão filosófica sobre os efeitos das Alterações Climáticas nas interações humanas com a Natureza considera que os problemas fundamentais estão ligados à (crescente) (in)justiça distributiva espaciotemporal. No entanto, o autor chama a atenção para o facto de a perda da biodiversidade por extinção antropogénica também ser um problema ético (Shue, 2005: 459).

Na linha do que Pickett \& Ostefeld (1995) já haviam referido - o problema hodierno é o descontrolo anormal da taxa atual de extinção, com um fluxo excessivamente rápido e com grande extensão espacial, Shue (2005) argumenta que o aumento de concentração dos GEE, resultado das atividades antrópicas, conduz a alterações rápidas do clima e à deterioração e/ou perda de habitats e, consequentemente, à extinção de espécies animais e vegetais por não terem tempo para se adaptar.

Perante tão complexa situação são muitas as questões que se impõem: Até que ponto é moralmente aceitável a interferência antropogénica no Ambiente? Até que ponto é moralmente aceitável a manipulação genética? Até que ponto é moralmente aceitável a manipulação climática? As respostas disponíveis são inúmeras e não convergentes, pois dependem dos valores, da perceção, da posicionalidade e da perspetiva mais antropocêntrica, mais biocêntrica ou mais ecocêntrica do seu autor. 
No gizar das políticas das alterações climáticas e/ou das políticas ambientais, mesmo considerando a inexistência de um modelo científico que abarque todas as variáveis e todas as incertezas inerentes, bem como a impotência preditiva da ecologia e/ou as limitações das teorias científicas (Shrader-Frechette, 2005), dever-se-á, a nosso ver, ponderar, de uma perspetiva holística, a dimensão espaciotemporal da ação antrópica em relação ao Ambiente, aos mais débeis, aos seres não-humanos e seus habitats, bem como às gerações vindouras, tendo em conta as implicações éticas.

A respeito, e no âmbito do dever ser, Callicott (2005) defende: "Uma coisa está correta quando tende para perturbar a comunidade biótica apenas em escalas espaciais e temporais normais. Está errada quando tende para outra coisa" (2005: 225).

De uma outra perspetiva Jonas ([1979] 1984) reformula o imperativo categórico Kantiano e defende o Princípio da Responsabilidade: "Age de tal modo que os efeitos da tua ação sejam compatíveis com a permanência de uma vida autenticamente humana na terra".

Næss (1986), por seu lado, vem propor o conceito de Autorrealização, conceito em que se escora a Ecosofia $\mathrm{T}^{1}$. A Autorrealização será o resultado de um processo individual de amadurecimento do "Eu" que, a partir do ego se vai alargando e integrando tudo aquilo com que se identifica. Assim, pode falar-se da transição do 'Ego' para o 'Eu social' e deste para o 'Eu ecológico', interiorizando-se simultaneamente o facto de a própria existência estar indelevelmente entrelaçada com o Todo, de que é parte (Mathews, 2005).

Este processo de amadurecimento traduz-se, defende Næss (1986), em um egoísmo ecológico e, consequentemente, leva a um comportamento de cuidado com a Natureza, visto ser o mais verdadeiro, profundo e próprio interesse do indivíduo. Afinal é da sua própria sustentabilidade que se trata.

Sabe-se hoje, conforme já referido, que o estilo de vida desenvolvido, particularmente a partir da Revolução Industrial, encetada pelos países afluentes (Cameron, 2004), tem efeitos antropogénicos transespaciais e transtemporais muito superiores à capacidade de regeneração natural do planeta, enquanto, simultaneamente, a grande maioria dos humanos não tem acesso aos recursos básicos para satisfazer as suas necessidades vitais.

1 Em lato sensu, pensamento filosófico que reflete harmonia ecológica ou equilíbrio. 'I call the ecosophy I feel at home by "Ecosophy T" (Næss, s/d [1986]:412). 'T' advém de Tvergastein, nome de uma montanha na Noruega onde Næss tinha a sua cabana. Era o seu local preferido para caminhar, refletir e meditar em comunhão com a natureza. Disponível on-line em: http://www.nytimes.com/2009/01/15/world/europe/15naess.html? r $=0$
Além disso, a comunidade humana, no geral, está longe de pensar seres humanos, não-humanos e na Natureza como partes integrantes e interdependentes de um Todo e de considerar que o Todo - e cada uma das partes tem estatuto moral próprio, pelo que, em consonância, a realização ou manutenção do seu bem-estar tem valor intrínseco. E a proteção do Todo requer ações concretas, justiça, respeito e responsabilidade aos níveis individual, social e ambiental. Em última instância, requer uma evolução no sentido de democracias-maisque-humanas (Hettinger, 2005).

A nosso ver, é necessário que a Ética Ambiental se (re)produza culturalmente. Urge que os valores ambientais se impregnem no tecido cultural das sociedades humanas e se traduzam no terreno. Desta forma, não apenas a aplicação das políticas climáticas e ambientais seria percecionada como um processo natural, como ainda seriam ultrapassados, em muito, os seus objetivos.

\section{Adaptação e Mitigação - Das Políticas, Mercados e Sustentabilidade}

\subsection{Em Portugal: Do PNAC à ENAAC}

Data de 2001 o primeiro Programa Nacional de Alterações Climáticas (PNAC), revisto e atualizado, de acordo com a Diretiva n. ${ }^{\circ}$ 2003/87/CE, do Parlamento Europeu e do Conselho, de 13 de outubro, pela Resolução do Conselho de Ministros (RCM) n. ${ }^{\circ}$ 119/2004.

Com a sua origem nas necessidades sentidas pela Comissão para as Alterações Climáticas (CAC) (19982012), ao verificar as insuficiências do PNAC (2004) e o consequente afastamento de Portugal do cumprimento das metas do Protocolo de Quioto (PQ), o PNAC (2006), veio atualizar o anterior, traduzindo uma política com consciência da situação ambiental.

Conforme a RCM n. ${ }^{\circ} 10423$, de agosto de 2006, refere no seu preâmbulo: "No contexto comunitário devem ter-se em conta as conclusões do Conselho de Ministros do Ambiente de Março de 2006, reafirmando a estratégia definida em Março de 2005 pelos Chefes de Estado e de Governo da União Europeia relativamente à necessidade de considerar, com todas as Partes à Convenção, acções futuras tendo em vista o objectivo último da Convenção - a estabilização da concentração de GEE na atmosfera a um nível que evite uma interferência antropogénica perigosa com o sistema climático" (Resolução do Conselho de Ministros n. ${ }^{\circ}$ 104/2006).

Considerando a situação local, o PNAC 2006 transportava para a legislação nacional as orientações, em conformidade com os então compromissos e princípios das políticas para as AC da UE.

Assim, foram estabelecidos para Portugal os instrumentos e mecanismos legais: i) o Plano Nacional de Atri- 
buição de Licenças de Emissão, o PNALE II, que impõe tetos às emissões de $\mathrm{CO}_{2}$ a um conjunto de instalações industriais, viabilizando a participação de Portugal no mecanismo de licenças de emissão europeias, o Comércio Europeu de Licenças de Emissão (CELE); e, ii) o Fundo Português de Carbono, que promove a aquisição de unidades de cumprimento no âmbito dos Mecanismos de Flexibilidade do PQ, bem como a redução adicional de emissões de gases com efeito de estufa através de projetos domésticos.

Além destes mecanismos, necessários à implementação e cumprimento do PQ, o PNAC 2006 estabelecia os meios e os instrumentos de avaliação e monitorização do processo para o cumprimento das metas assumidas, prevendo mesmo um plano de contingência, para que fossem respeitados os limites de emissões de GEE a que Portugal estava sujeito - para o cumprimento do PQ para o período 2008-2012, o Estado português não podia ultrapassar em mais de $27 \%$ as emissões antropogénicas de GEE registadas em 1990. Este valor está conforme o princípio do PQ e da Política Ambiental europeia: Responsabilidades comuns mas diferenciadas.

Verifica-se atualmente, de acordo com o Indicador de Cumprimento de Quioto, que Portugal foi um dos países que cumpriu as metas estabelecidas para o período 2008-2012. A este feito, no entanto e para além do referido, não terá sido alheia a profunda crise económica atravessada pelo país.

Em dezembro de 2008, o Parlamento Europeu aprova o Pacote Clima-Energia: "três vintes" até 2020, acordado com o Conselho da Europa sobre: i) comércio de licenças de emissão; ii) contribuição de cada Estado-Membro para a redução das emissões, captura e armazenagem de carbono; iii) energia proveniente de fontes renováveis; iv) propostas relativas às emissões de $\mathrm{CO}_{2}$ dos automóveis e às especificações para os carburantes.

Em abril de 2010 foi submetida e adotada como RCM n. ${ }^{\circ}$ 24/2010, a Estratégia Nacional de Adaptação às Alterações Climáticas (ENAAC) considerada "o primeiro passo na preparação de Portugal para os desafios da adaptação às alterações climáticas" (CECAC-APA, 2011:7).

A ENAAC está enformada por quatro objetivos primordiais:

- Informar e Conhecer - buscando desenvolver uma base científica e técnica sólida;

- Reduzir a Vulnerabilidade e Aumentar a Capacidade de Resposta - identificando, definindo prioridades e aplicando as principais medidas de adaptação "em particular de fenómenos meteorológicos extremos" (Resolução do Conselho de Ministros n. ${ }^{\circ}$ 24/2010);
- Participar, Sensibilizar e Divulgar - junto de todos os agentes sociais, buscando a sua participação;

- Cooperação internacional.

Na sequência da Conferência de Copenhaga (COP 15), em dezembro de 2009, por força do Despacho n. ${ }^{\circ}$ 15296/2010, de 11 de outubro, são estabelecidas para Portugal as normas de aplicação da Iniciativa Portuguesa de Implementação Imediata (FastStart) no que concerne às $\mathrm{AC}$, sendo também determinada a constituição de um grupo de trabalho (GT-FastStart) com a responsabilidade pela sua execução. O GT-FastStart é composto por representantes do Instituto Português de Apoio ao Desenvolvimento, I.P. (IPAD) e da Agência Portuguesa do Ambiente, I.P (APA). A partir de setembro de 2011, a política climática em Portugal passa a estar concentrada na APA.

Com o objetivo de "colocar a economia nacional no sentido da sustentabilidade, da eficiência e da competitividade", para o período pós-2012, a RCM n. ${ }^{\circ}$ 93/2010, vem estabelecer a criação de novos instrumentos de apoio para as políticas de Alteração Climática: i) o Roteiro Nacional de Baixo Carbono 2020 (RNBC 2020), ii) a elaboração de planos sectoriais de baixo carbono para cada ministério, e iii) o Programa Nacional para as Alterações Climáticas para o período 2013-2020 (PNAC 2020).

Os impulsos políticos ao nível do Estado central, no âmbito da estratégia relativa às $\mathrm{AC}$ - que se desdobram numa multiplicidade de programas, planos, decisões, procedimentos, etc., nem sempre consonantes, aos vários níveis institucionais - conforme se pode verificar por uma leitura atenta, são recheados de urdiduras semânticas, não integram saberes locais, privilegiam espaços de informação a espaços de diálogo polifónico com os atores envolvidos no terreno e, atualmente, vão no sentido de concentrar esforços e recursos na intervenção pós-desastre, se comparado com os esforços na sua prevenção (e.g.: Vide Objetivos primordiais da ENAAC).

\subsection{Da Sustentabilidade, Políticas e Mercados}

Como referido, na UE, são as políticas europeias que orientam, impulsionam e condicionam as políticas dos Estados Membros. Estes, obrigatoriamente, devem transpor para as legislações nacionais as diretrizes europeias (o que também não é um processo isento de dificuldades e tensões).

A política ambiental, e em particular a política climática aqui em análise, na busca de soluções para os efeitos das Alterações Climáticas e a sua prevenção, é enquadrada pelo princípio da sustentabilidade, posto na ordem do dia mundial em 1987 pela mão do relatório Our Common Future (Brundtland, 1987), depois assumido pela União Europeia e, mais tarde, consagra- 
do no texto constitucional em Portugal (Canotilho, 2010), definindo-se, assim, como um princípio estruturante da organização do(s) Estado(s) e, consequentemente, das sociedades.

Embora o relatório das Nações Unidas Back to Our Common Future (UNDESA, 2012), sobre os resultados da Conferência RIO+20, confirme não terem sido atingidas as metas da RIO92, afirma serem vários os caminhos ainda possíveis para atingir o Desenvolvimento Sustentável (DS). Paradoxalmente, tem-se vindo a assistir, no entanto, à pressão continuada de posturas hegemónicas, pouco disponíveis para atender a outros conhecimentos, necessidades ou interesses, a que se aliam, entre outros, as dificuldades no diálogo entre os atores (Santos, 2005). O que releva - e basta uma leitura atenta aos press release que foram sendo disponibilizados durante a Cimeira para o verificar - são os problemas (eficácia/resultado) no delineamento e na praxis das políticas para a sustentabilidade e as dificuldades para, em conjugação de interesses, trilhar esse(s) caminho(s).

A atual crise global, que põe em causa o DS, é a evidência de que, para que as políticas sejam eficazes (sustentáveis) na prática, é necessário equacionar-se a sustentabilidade das políticas. Por isso a importância de delinear políticas - respostas inovadoras - que, tendo em consideração os contextos ambientais, integrem não apenas as racionalidades, as crenças e os valores locais, mas também procedimentos e tecnologias acessíveis às populações-alvo dessas políticas, sob pena de as isolar.

A este respeito, Egiziabher (2004) observa que os camponeses (entendam-se os submetidos ao poder de outrem) “...não são impermeáveis a novos conhecimentos e maneiras de pensar, desde que minimamente acessíveis, apresentando-se sob formas que lhes sejam relativamente compreensíveis - tal como acontece a toda a gente. [...] Os camponeses não são conservadores que ficam de fora apenas para ficar de fora; eles representam a maioria, a nível global, que tem sido marginalizada pela agressiva minoria globalizadora. Por esta razão, os camponeses pretendem continuar a controlar o processo que se destina a tirá-los da pobreza - tal como qualquer de nós" (2004: 405).

A sustentabilidade das políticas para a sustentabilidade está, assim, interligada com uma praxis que invista nas populações locais (e as respeite), considerando, por um lado, as variáveis climáticas, ambientais, tecnológicas e económicas globais, e, por outro lado, integrando as variáveis ambientais, tecnológicas, económicas e socioculturais locais na esteira do é referido referido pelo Worldwatch Institute em Toward a Transatlantic Green New Deal: Tackling the Climate and Economic Crises (Frentch et al., 2009).

Foi apenas em fevereiro de 2010 que a Comissão Europeia criou a Direção-Geral para a Ação Climática, com o propósito de conduzir as negociações internacionais sobre o clima, ajudar a UE a lidar com as consequências das Alterações Climáticas e a cumprir as metas para 2020, bem como desenvolver e implementar o Sistema de Comércio de Emissões da UE.

Para além de definir estratégias e coordenar a política ambiental e a política climática que ainda despontam, a UE é mandatada para negociar e ratificar, em nome dos Estados Membros, com países terceiros. Tal foi o caso da Decisão 2002/358/CE do Conselho, de 25 de Abril de 2002 (CE, 2002) relativa à aprovação, em nome da Comunidade Europeia, do Protocolo de Quioto (PQ) (UNFCCC, 1998), resultante da III Conferência das Partes (COP3); da Convenção-Quadro das Nações Unidas sobre as Alterações Climáticas (CQNUAC), em 1997; e ao cumprimento conjunto dos respetivos compromissos, sob o princípio "responsabilidades comuns mas diferenciadas", já acima referido.

A partir do PQ, um dos instrumentos jurídicos internacionais mais importantes na luta contra as Alterações Climáticas, os países industrializados, para além de reconhecerem a sua responsabilidade pelos altos níveis de produção de GEE atuais, assumem que as suas emissões totais devem ser reduzidas em, pelo menos, $5 \%$ em relação aos níveis de 1990 , durante o período 2008-2012.

Com o objetivo de estabilizar as emissões de determinados GEE são, então e pela primeira vez, definidos mecanismos de mercado para permitir a viabilização e o financiamento deste processo: i) Emissions trading conhecido por "Mercado do Carbono"; ii) Clean Development Mechanism; iii) Joint Implementation. Estes mecanismos, no entanto, não colhem aprovação unânime, sendo mesmo fonte de grande polémica, pois entre os movimentos ambienta-listas, como o Carbon Trade Watch, há os que os entendem como um embuste e um perpetuar e aumentar das desigualdades sociais e agressões ambientais. Aliás, neste sentido é interessante o vídeo "The Story of Cap \& Trade", disponível on-line em https://www.youtube. com/watch?v=ZYi78LaY8u4.

No âmbito das políticas europeias de combate às Alterações Climáticas e com o horizonte de 2020, Portugal viu recentemente aprovada uma ambiciosa Estratégia Nacional para a energia com a aprovação do Plano Nacional de Ação para as Energias Renováveis (s/d), ao abrigo da Diretiva 2009/28/CE.

É neste contexto, e considerando os diferentes níveis de intervenção - Global; Regional e Local - que a capacitação competente (Empowerment) de indivíduos e populações para as tomadas de decisão locais e para a assunção do controlo dos processos em que estão envolvidos é considerada um fator crítico para a redução do risco de desastres (Field et al., 2012). Daí, também, o apelo crescente a uma cidadania participativa ambientalmente responsável. 
Aliás, deste convocar geral, no seguimento da Carta da Terra (Earth Charter, 2000) e da Conferência Rio 92, já faziam eco a Agenda 21 e a Convenção de Aarhus (1998).

Assim, importa sublinhar Alves et al. (2012): “... é necessário construir para o século XXI uma cidadania simultaneamente social e política, uma cidadania ambiental que encoraje a participação e valorize o diálogo e articulação entre distintos saberes-poderes." (2012:53).

\section{Da Sociedade de Risco - Reflexividade, Estratégias e Saberes}

\subsection{Risco e Reflexividade}

Giddens (1991) entende que a sociedade moderna reflexiva se constitui e se produz pelo conhecimento reflexivo aplicado, e na qual as ciências sociais, mais do que as naturais, estão profundamente implicadas. Para o autor, mais do que uma característica definidora de toda a ação humana, a reflexividade, na modernidade, integra a "própria base da reprodução do sistema, de forma que o pensamento e a ação estão constantemente refratados entre si [sendo] as práticas sociais constantemente examinadas e reformadas à luz de informação renovada sobre estas próprias práticas, alterando assim constitutivamente seu caráter" (Giddens, 1991:39).

Para Beck et al. (1995) "'Modernização reflexiva" significa a possibilidade de uma (auto)destruição criativa para toda uma era: aquela da sociedade industrial. O "sujeito" dessa destruição criativa não é a revolução, não é a crise, mas a vitória da modernização ocidental" (Beck et al., 1995:13).

O dinamismo da modernidade é explicado por Giddens (op. cit., 1991) pela interceção de três instituições, nomeadamente i) os mecanismos de desencaixe ii) os sistemas peritos e iii) a apropriação reflexiva do conhecimento. Nas sociedades modernas, em contraste com as sociedades tradicionais e pré-modernas, assiste-se a um distanciamento entre o tempo e o espaço, o que permite situar as instituições e o desenvolvimento de mecanismos de desencaixe, como as fichas simbólicas (e.g. o dinheiro) e os sistemas peritos, que retiram as relações sociais do contexto tornando-as dependentes de uma atitude de confiança, ou falta dela, quer nos sistemas abstratos desencaixados, quer nas pessoas (e.g. conhecimentos técnicos específicos) e, a apropriação reflexiva do conhecimento.

A relação da modernidade com a reflexividade é caracterizada pelos pressupostos da reflexividade revisitada e indiscriminada bem como pela reflexão sobre a natureza da própria reflexão. Estas "reivindicações de conhecimento" são, de acordo com Giddens (1991), filtradas por quatro ordens de fatores: a) o poder diferencial, b) o papel dos valores, c) o impacto das consequências não pretendidas e, d) a circulação do conhecimento social na hermenêutica dupla. i.e.: "o conhecimento reflexivamente aplicado às condições de reprodução do sistema altera intrin-secamente as circunstâncias às quais ele originariamente se referia" (op. cit., 1991:52).

Beck et al. (op. cit., 1995), no entanto, chamam a atenção para o facto de que, embora as teorias da modernização reflexiva de Giddens (1991) e Beck et al. (1995) relevem e reflitam sobre o declínio das estruturas sociais e culturais, não têm em devida consideração a crescente imposição quer das estruturas das tecnologias de informação e comunicação, quer o seu papel nas estruturas culturais que, defende o autor, implicam a necessidade de uma reflexividade mais fina.

De uma perspetiva distinta da reflexividade cognitiva situada nas estruturas sociais - proposta por Giddens (1991), Bourdieu (1980a) e Beck et al. (1995) propõem os conceitos de habitus e de campo como instrumentos para a observação da realidade social. Bourdieu (1980a) defende que o ator social é, ele próprio, parte da produção das estruturas sociais, sendo as estruturas sociais resultado e meio reflexivo da ação. No entanto, é uma reflexividade situada nas categorias impensadas, nos esquemas classificatórios ou disposições, determinantes das práticas autoconscientes e das suas representações, determinadas, por sua vez, pela realidade social. O habitus só existe quando contextualizado e atua no sentido da manutenção ou transformação (construção) das relações e dos recursos, que determinam (e são determinados por) a produção dos conhecimentos, seja o senso comum, o científico, o religioso ou outro.

De acordo com Lahire (2005), "a teoria do habitus de Pierre Bourdieu toma também como garantida a ideia da transferibilidade ou da transponibilidade e do carácter 'generalizável' dos esquemas, ou disposições, socialmente constituídos" (2005: 23). Ponderando o que pode ser considerado como a dinâmica da unicidade plural interna do indivíduo, Lahire propõe revisitar o habitus defendendo a existência de uma pluralidade disposicional - disposições para crer e disposições para agir - e contextual - a multiplicidade dos contextos das disposições. Para o autor, "estudar o social individualizado, ou seja, o social refractado num corpo individual que tem a particularidade de atravessar instituições, grupos, campos de forças e de lutas ou cenas diferentes, é estudar a realidade social na sua forma incorporada, interiorizada" (2005:14).

A experiência vivida (Erlebnisse, palavra alemã que significa mais do que a aglutinação de Erfahrung [experiência] e Leben [vida] significando algo que se sente profundamente ao ser vivido), segundo Jodelet (2006), é enformada por representações sociais e categorizações que sustentam o sentido do desenvolvimento da experiência, atuando, assim, como mediadora 
na construção do conhecimento e do senso comum. Para Jodelet (2006:33), a experiência vivida "pode ser o cadinho de enriquecimento, de descoberta e de criação". Enquadrada pela Teoria da Representação Social, a autora fundamenta, em Place de l'expérience vécue dans le processus de formation des représentations sociales, (2006), que a experiência vivida pode ser "revestida", aparentando ser a ponte entre o social e o individual, entre o emocional/sensorial e o cognitivo, entendido como o sistema global de representações.

Ora, de uma outra perspetiva, o facto de o capital social considerar o modo das interações individuais e a forma como os atores se ligam e cooperam (ou não) - quer aos vários níveis do social, quer nos aspetos formais $\mathrm{e}$ informais das relações sociais e das sociedades - tornamno foco da nossa lupa.

\subsection{Do Capital Social e da Confiança}

Partindo do pressuposto de que as AC se fazem presentes pelos seus efeitos, nem sempre diretos e tendencialmente diluídos no tempo, os estudos sobre a perceção - do significado e do risco - das AC junto dos atores locais, ao darem visibilidade a processos sociais e a crenças, para além de uma melhor compreensão, possibilitarão a criação de respostas mais robustas para lidar com o fenómeno (Alves et al., 2014).

Nas últimas décadas - tendo em conta a variedade e a variabilidade de publicações dedicadas existentes, particularmente no âmbito da gestão ambiental e da gestão de recursos - verifica-se que o conceito de capital social se tornou polo de atração da atenção de políticos e cientistas. Conceito polissémico e multidimensional pode ser rastreado até Aristóteles (Ishihara \& Pascual, 2008). No entanto, esta atenção pode ser resultado das motivações ideológicas, sobretudo liberais, que relevam dos estudos do capital social (Higgins, 2005). Aliás, isto mesmo parece ser confirmado com a edição pelo World Bank, em 1999, de Social Capital, a Multifaceted Perspective.

Contudo, de acordo com a literatura (Davis, 2001; Paiva, 2008), parece haver duas perspetivas ideológicas influentes entre os grandes teóricos da construção do conceito: i) a já referida perspetiva neoliberal, que, como autores seminais, conta, entre outras importantes contribuições, com Coleman (1988) e Putman (1995); e ii) a perspetiva neo-marxista, cujo principal representante é Bourdieu (1980a; 1980b).

Conceito polémico, polissémico e sem um recorte claro, "na maior parte dos casos as várias aceções consideram quase sempre três dimensões constituintes: componentes (redes, normas e sanções); nível de análise (micro, meso e macro); e carácter ou função (fechamento, abertura e ligação)" (Paiva, 2008:20).

Resultante de uma pesquisa exaustiva sobre o conceito de capital social, Adler \& Know (2000) procuraram fazer uma síntese dos trabalhos teóricos levados a cabo pelas várias disciplinas das ciências sociais, no sentido de desenvolverem um enquadramento conceptual comum que incluísse as fontes, os benefícios e os riscos do conceito.

Nesse artigo, os autores propõem uma definição que procura integrar todas as principais contribuições: "Social capital is a resource for individual and collective actors created by the configuration and content of the network of their more or less durable social relations" (Adler \& Know, 2000:92).

Esteio e fruto do capital social aparenta ser a confiança (Fig. 1).

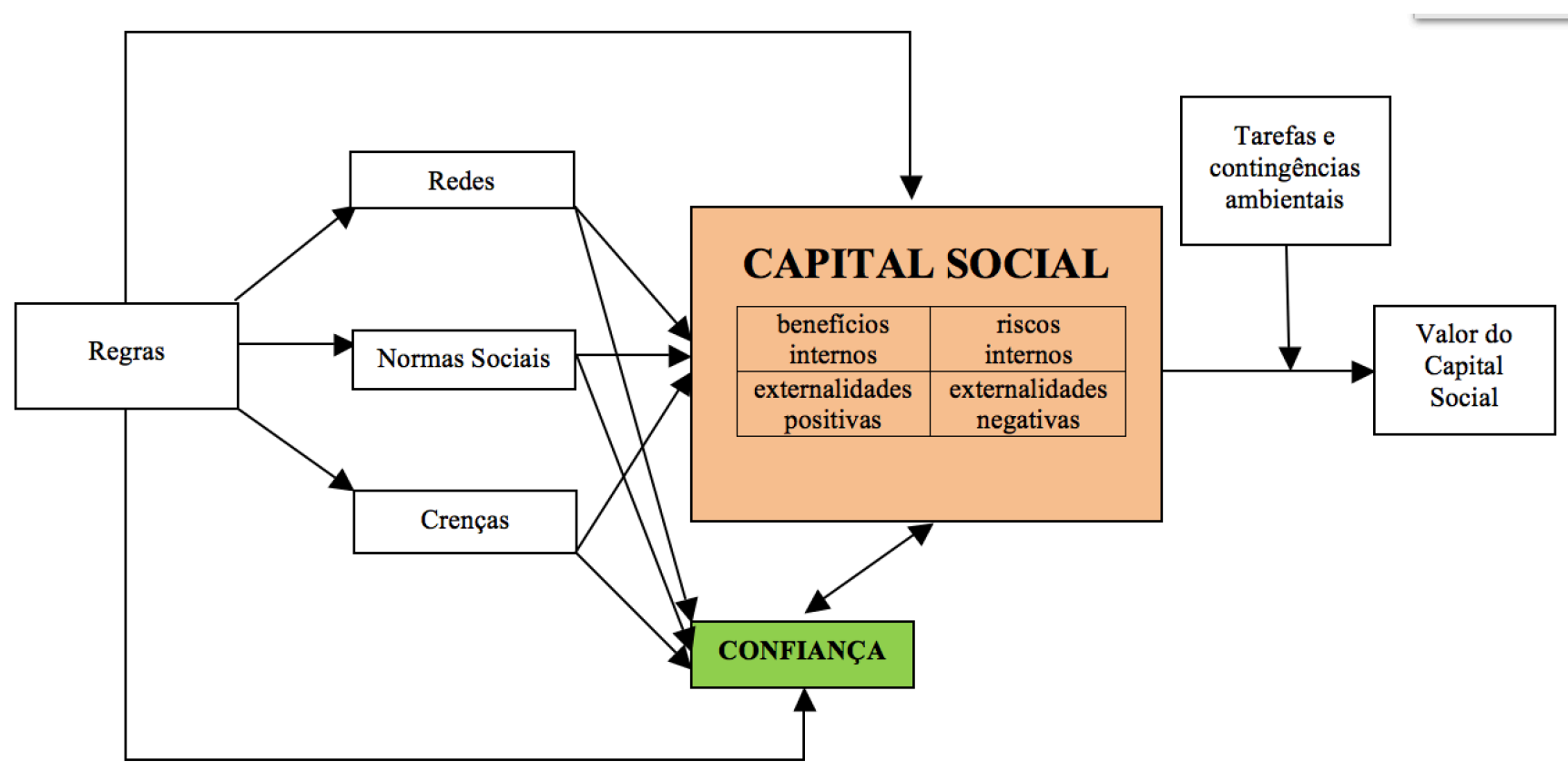

Figura 1 - Capital Social: Mapa conceptual. Adaptado de Adler \& Kwon (2000).

Figure 1 - Social Capital: Conceptual map. Adapted from Adler \& Kwon (2000). 
A confiança é, por si só, um conceito multidimensional e polissémico. Giddens (1991) dá-nos conta da desconstrução da noção de confiança, aos vários níveis do social e das relações sociais, em inter-relação com as noções de crença, de perigo e de risco.

Para Giddens (1991), a noção de confiança: i) relaciona-se com a ausência, do sujeito e/ou do objeto, no tempo e no espaço; ii) está vinculada à contingência; iii) é o elo entre fé e crença. "A confiança pode ser definida como crença na credibilidade de uma pessoa ou sistema, tendo em vista um dado conjunto de resultados ou eventos, em que essa crença expressa uma fé na probidade ou amor de um outro, ou na correção de princípios abstratos (conhecimento técnico)" (1991:36).

Retemos, no entanto, que: "os diferentes campos (político, científico, etc.) definem modos específicos de dominação e são, por isso mesmo, campos de forças (assimétricas) e de lutas para conservá-los ou transformá-los" (Silva \& Alves, 2011:1211).

\subsection{Saberes e Racionalidades Plurais: Rivais ou Complementares?}

A situação hodierna com que nos confrontamos requer o impulso de estratégias globais tanto quanto a construção de respostas locais que considerem e incluam as experiên-cias e os saberes espaciotemporalmente localizados dos agentes e das racionalidades leigas para lidar com o fenómeno das AC e seus efeitos.

Quando Foucault (1992) falou sobre Erudição e saberes submetidos, no âmbito de um curso no Collège de France, entre fins de 1975 e meados de 1976, designou os saberes das pessoas - diferentes do senso comum como saberes submetidos. Com estes saberes submetidos Foucault referia-se, por um lado aos saberes "sepultados" - conteúdos históricos, branqueados ou dissimulados, dentro de coerências funcionais ou sistematizações formais e, por outro, aos saberes "submetidos" particulares, locais, singulares, desclassificados. Ambos - submetidos e sepultados - embebidos do saber histórico das lutas (1992:21-22).

Foucault (1992), perante a unidirecionalidade hegemónica da ciência, afirma a igualdade de valor de todos os conhecimentos, espelhados nos discursos, enquanto conceções plurais do mundo, da vida e dos fenómenos (Alves, 2011; Silva \& Alves, 2011).

Assim perspetivado, o conhecimento leigo, cujas dinâmica e reconstrução se alicerçam na interação, é válido porque, concordamos com Alves (2011), produz sentido e explica os fenómenos do mundo e da vida, sustentando a ação e a interação social.

Contudo, os saberes submetidos têm vindo a tomar denominações várias, que procuram enaltecer algum aspeto ou propriedade do conhecimento assim designado. Delicado et al. (2012:438) fazem essa compilação, que aqui sumariamente revisitamos: "conhecimento ecológico tradicional" (Houde, 2007); "conhecimento indígena" (Bohensky \& Maru, 2011; Bohensky et al., 2013); "conhecimento local" (Paton \& Fairbairn-Dunlop, 2010), "conhecimento dos stakeholders" (Edelenbos et al., 2011); e "conhecimento leigo" (Edelenbos et al., 2011; Brace \& Geoghegan, 2010; Alves et al., 2014)".

Numa perspetiva diacrónica do saber científico, constatase que: "na ciência moderna a ruptura epistemo-lógica simboliza o salto qualitativo do conhecimento do senso comum para o conhecimento científico; na ciência pós-moderna o salto mais importante é o que é dado do conhecimento científico para o conhecimento do senso comum" (Santos, 1999:57). No entanto - não cabendo aqui qualquer análise genealógica dos diferentes saberes, perante a rivalidade de poderes e a dicotomia entre o conhecimento perito e o conhecimento leigo - levantam-se, entre muitas outras, as seguintes questões: De que modo são estes saberes chamados a participar na produção de conhecimento? Como se relacionam e/ou interinfluenciam? E, exatamente, que saber/poder é que se (re)produz?

Lidskog (2008), num inspirado artigo intitulado Scientised citizens and democratised science. Reassessing the expert-lay divide, apresenta-nos uma revisão crítica dos desenvolvimentos recentes das posições racionalistas construtivistas, no referente à relação entre a ciência e o público, no âmbito da ciência e da gestão do risco, a partir de três propostas - i) New Production of Knowledge; ii) Postnormal Science; iii) Scientific Citizenship - de onde resulta evidente a preocupação pragmática da ciência, por um lado e, por outro, a gradativa evolução de um novo modo de produzir ciência, onde cidadãos cada vez mais informados e reflexivos têm vindo a ser chamados a contribuir, em ágoras progressivamente alargadas aos cidadãos instruídos, aos representantes da sociedade civil e aos cidadãos leigos.

No entanto, Lidskog (2008) chama a atenção para a "necessidade de desenvolver entre a ciência e os cidadãos novas relações que não reproduzam a dicotomia entre especialistas e leigos. Os espaços criados para negociação e deliberação não deverão ser determinados por factos produzidos cientificamente. Pelo contrário, a ciência e a gestão de riscos devem ser tornadas mais acessíveis, mesmo nos casos em que os riscos são alegadamente invisíveis para os cidadãos" (Lidskog, 2008:84).

Com uma perspetiva dialógica polifónica, face à postura dos poderes hegemónicos e da teoria geral, Santos et al. (2004) propõe a tradução como o instrumento para a inteligibilidade das experiências e a completude dos saberes, uma zona de contacto que pode viabilizar a inteligibilidade entre saberes e práticas, simultaneamente mantendo as identidades e as autonomias. 
Santos (2005) considera que, embora precário, o trabalho de tradução entre saberes, a partir da imaginação epistemológica, conduz à justiça cognitiva e, a partir da imaginação democrática, a tradução entre práticas e os seus atores possibilitará abrir caminho para uma justiça social global. O trabalho de tradução assim concetualizado - ao exigir um esforço de aprendizagem recíproca, como refere Santos (2005), para a partilha de experiências e de racionalidades plurais - poderá ser o instrumento motor de uma transformação de valores e instituições na sociedade, no sentido do respeito pelo ambiente, pelos saberes, pelos géneros e pelas culturas.

Por outro lado, e em contraste com a racionalidade científica ou técnica, o conceito de racionalidade leiga (Alves, 2011; Silva \& Alves, 2011) diz respeito a uma lógica plural, complexa, multidimensional, prenhe da subjetividade da cultura interiorizada pelo sujeito e refletida no pensamento e ação leigos em esquemas (estratégias) orientados para objetivos.

\section{Concluíndo}

Com uma matriz de conceção inclusiva, constituída por uma pluralidade de tipos e fontes de saberes, particular- mente quando as neurociências e as nanotecnologias se perfilam como um imenso campo de respostas (e de questões), releva, a nosso ver, o potencial heurístico do conceito das racionalidades leigas.

Assim, para além de considerarmos a incompletude dos saberes, a assimetria de poderes e de modos de vida, a incerteza, a espaciotemporalidade, o desconhecimento, a complexidade e a multidimensionalidade interinfluente muitas vezes conflituosa ou paradoxal dos sistemas climático, ambiental e socioculturais, de que o sujeito plural é ator reflexivo ativo, a reflexão sobre a produção do conhecimento leigo, como uma forma de conhecimento válida, e sobre as suas práticas nos seus contextos de produção espaciotemporalmente recortados contribuirá para compreendermos como as pessoas percecionam e vivem com as mudanças climáticas e como lidam com os seus efeitos.

Em suma, procurar compreender os mecanismos das racionalidades leigas relacionadas com as Alterações Climáticas nos seus contextos espaciotemporais, significa compreender como se pensa e vive a Vida. Hic et Nunc.

\section{Referências bibliográficas}

Abe, Y. (1993) - Physical state of the very early Earth. Lithos, 30(3-4):223-235. DOI: 10.1016/0024-4937(93)90037-D.

Adler, P.S.; Kwon, S-W. (2000) - Social Capital: The Good, the Bad, and the Ugly. In: Eric L. Lesser (ed.), Knowledge and Social Capital: Foundations and Applications, pp.89-115, Butterworth-Heinemann, Boston, MA, U.S.A. DOI: 10.2139/ ssrn. 186928.

Alves, F. (2011) - A Doença Mental Nem Sempre é Doença. Racionalidades Leigas sobre a Saúde e Doença Mental - Um Estudo no Norte de Portugal. 293 p., Edições Afrontamento, Porto, Portugal. ISBN: 978-9723611335.

Alves, F.; Araújo, M.J.; Azeiteiro, U.M. (2012) - Cidadania ambiental e participação: o diálogo e articulação entre distintos saberes-poderes. Revista Saúde em Debate (ISSN: 0103-1104), 36:46-54, Centro Brasileiro de Estudos de Saúde, Rio de Janeiro, RJ, Brasil. Disponível on-line em https://repositorio aberto.uab.pt/bitstream/10400.2/3160/3/RevistaSaudeDebate_pd f.pdf

Alves, F.; Caeiro, S.; Azeiteiro, U.M. (2014) - Lay Rationalities of Climate Change. International Journal of Climate Change Strategies and Management (ISSN: 1756-8692), 6(1):1756-8692, Emerald Group Publishing Limited, Bingley, U.K. Disponível on-line em http://www.emeraldinsight.com/ journals.htm? issn $=1756-8692 \&$ volume $=6 \&$ issue $=1$.

Aristóteles (2009) - Ética a Nicómaco. 320 p., Quetzal Editores, Lisboa, Portugal. ISBN: 978-9725648032

Baudouin-Cornu, P.; Thomas, D. (2007) - Oxygen at life's boundaries. Nature, 445:35-36. DOI: 10.1038/nature05521.

Beck, U.; Giddens, A.; Lash, S. (1995) - Modernização Reflexiva Política, Tradição e Estética na Ordem Social Moderna. 264p., Editora Unesp, São Paulo, SP, Brasil. ISBN: 8571391432.

Bijma, J.; Pörtner H-O.; Yesson C.; Rogers A.D. (2013) - Climate change and the oceans - What does the future hold? Marine Pollution Bulletin, 74(2):495-505. DOI: 10.1016/j.marpolbul. 2013.07.022.
Bohensky, E.L.; Butler, J.R.A.; Davies, J. (2013) - Integrating indigenous ecological knowledge and science in natural resource management: perspectives from Australia. Ecology and Society, 18(3):20. DOI: 10.5751/ES-05846-180320.

Bohensky, E.L.; Maru, Y. (2011) - Indigenous Knowledge, Science, and Resilience: What Have We Learned from a Decade of International Literature on "Integration"? Ecology and Society, 16(4):6. DOI: $10.5751 /$ ES-04342-160406.

Bourdieu, P. (1980a) - Le Sens pratique. 480p., Les Éditions de Minuit, Paris, France. ISBN: 2707302988.

Bourdieu, P. (1980b) - Le capital social: notes provisoires. Actes de la Recherche en Sciences Social (ISBN: 0026-9395), 31:2-3, Bouquiner Éditeur, Paris, France. Disponível on-line em http://www.persee.fr/web/revues/home/prescript/article/arss_03 35-5322_1980_num_31_1_2069

Brace, C.; Geoghegan, H. (2010) - Human geographies of climate change: Landscape, temporality, and lay knowledges. Progress in Human Geography, 35(3):284-302. DOI: 10.1177/ 0309132510376259.

Broecker, W.S. (1991) - The Great Ocean Conveyor. Oceanography, 4(2):79-89. DOI: 10.5670/oceanog.1991.07.

Broecker, W.S. (2006) - Was the Younger Dryas Triggered by a Flood? Science, 312(5777):1146-1148. DOI: 10.1126/science. 1123253.

Brundtland, G.H. (coord.) (1987) - Our Common Future. Report of the World Commission on Environment and Development, transmitted to the General Assembly as an Annex to document A/42/427 Development and International Cooperation: Environment. 245p., United Nations. Disponível on-line em http://conspect.nl/pdf/Our_Common_Future-Brundtland_Report _1987.pdf.

Butterfield, N.J. (2007) - Macroevolution and macroecology through deep time. Palaeontology, 50(1):41-55. DOI: 10.1111/ j.1475-4983.2006.00613.x. 
Callicott, J.B. (2005) - A ética da terra. In: D. Jamieson (Coord.), Manual de Filosofia do Ambiente, pp.213-226, Lisboa, Portugal. ISBN: 978-9727717729.

Came, R.E.; Eiler, J.M.; Veizer, J.; Azmy, K.; Brand, U.; Weidman, C.R. (2006) - Coupling of surface temperatures and atmospheric $\mathrm{CO}_{2}$ concentrations during the Palaeozoic era. Nature, 449 (7159):198-201. DOI: 10.1038/nature06085.

Cameron, R. (2004) - História Económica do Mundo - De uma Forma Concisa, de há 30000 Anos até ao Presente. 496 p., Publicações Europa-América, Sintra, Portugal. ISBN: 9789721044784.

Canotilho, J.J.G. (2010) - O Princípio da sustentabilidade como Princípio estruturante do Direito Constitucional. Tékhne (Revista de Estudos Politécnicos) (ISSN: 1645-9911), VIII(13):007-018, Instituto Politécnico do Cávado e do Ave, Barcelos, Portugal. Disponível on-line em http://www.scielo. oces.mctes.pt/pdf/tek/n13/n13a02.pdf.

CE (2002) - Decisão do Conselho 2002/358/CE, de 25 de Abril de 2002, relativa à aprovação, em nome da Comunidade Europeia, do Protocolo de Quioto da Convenção-Quadro das Nações Unidas sobre as alterações climáticas e ao cumprimento conjunto dos respectivos compromissos. Jornal Oficial da União Europeia - Edição em língua portuguesa (ISSN: 17252601), L130(15/05/2002):1-3. Disponível on-line em http://eurlex.europa.eu/LexUriServ/LexUriServ.do?uri=CELEX:32002D 0358:PT:HTML.

CECAC - APA (2011)- Ponto da situação das politicas de alterações climáticas em Portugal. 31 p., Comité Executivo da Comissão para as Alterações Climáticas (CECAC) / Agência Portuuesa do Ambiente (APA), Lisboa, Portugal. Disponível on-line em http://www.cumprirquioto.pt/documents/List.action.

Cockell, C.S.; Raven, J.A. (2007) - Ozone and life on the Archaean Earth. Philosophical Transactions of the Royal Society Mathematical, Physical \&Engineering Sciences, 365:18891901. DOI: 10.1098/rsta.2007.2049.

Coleman, J.S. (1988) - Social Capital in the creation of human capital. American Journal of Sociology (ISSN: 0002-9602), 94(suppl.):S95-S120, The University of Chicago Press, Chicago, IL, U.S.A. Disponível on-line em http://www.jstor.org/discover $/ 10.2307 / 2780243$ ?uid $=2 \&$ uid $=4 \&$ sid $=21104278769477$

Crowe, S.A.; Døssing, L.N.; Beukes, N.J.; Bau, M.; Kruger, S.J.; Frei, R.; Canfield, D.E. (2013) - Atmospheric oxygenation three billion years ago. Nature, 501(7468):535-538. DOI: 10.1038/ nature 12426.

Delicado, A.; Schmidt, L.; Guerreiro, S.; Gomes, C. (2012) Pescadores, conhecimento local e mudanças costeiras no litoral Português. Revista de Gestão Costeira Integrada, 12(4):437451. DOI: $10.5894 /$ rgci349.

Des Marais, D.J. (2000) - When Did Photosynthesis Emerge on Earth? Science, 289(5485):1703-1705. DOI: 10.1126/science. 289.5485.1703.

Drake, M.J. (2005) - Origin of water in the terrestrial planets. Meteoritics \& Planetary Science, 40(4):519-527. DOI: 10.1111/j.1945-5100.2005.tb00960.x.

Dudley, R. (1998) - Atmospheric oxygen, giant Paleozoic insects and the evolution of aerial locomotor performance. Journal of Experimental Biology (ISSN: 0022-0949), 201:1043-1050, Company of Biologists, Cambridge, U.K. Disponível on-line em http://jeb.biologists.org/content/201/8/1043.full.pdf.

Earth Charter (2000) - The Earth Charter. 4p., The Earth Charter Initiative. Disponível on-line em http://www.earthcharter inaction.org/invent/images/uploads/echarter_english.pdf.

Edelenbos, J.; Van Buuren, A.; Van Schie, N. (2011) Co-producing knowledge: joint knowledge production between experts, bureaucrats and stakeholders in Dutch water management projects. Environmental Science \& Policy, 14(6):675-684. DOI: 10.1016/j.envsci.2011.04.004.

Egiziabher, T.B.G. (2004) - Uma globalização baseada nas pessoas. (397-416) In: B.S. Santos (org.), Semear outras soluções. Os Caminhos da Biodiversidade e dos Conhecimentos Rivais. Edições Afrontamento, Porto, Portugal. ISBN: 9789723607208.

Fabry, V.J.; Seibel, B.A.; Feely, R.A.; Orr, J.C. (2008) - Impacts of ocean acidification on marine fauna and ecosystem processes. ICES- Journal of Marine Science, 65(3):414-432. DOI: 10.1093/icesjms/fsn048.

Falkowski, P.G. (2006) - Tracing Oxygen's Imprint on Earth's Metabolic Evolution. Science, 311(5768):1724-1725. DOI: 10.1126/science. 1125937.

Field, C.B.; Barros, V.; Stocker, T.F.; Qin, D.; Dokken, D.J.; Ebi, K.L.; Mastrandrea, M.D.; Mach, K.J.; Plattner, G.-K.; Allen, S.K.; Tignor, M.; Midgley, P.M. (eds.) (2012) - Managing the Risks of Extreme Events and Disasters to Advance Climate Change Adaptation. A Special Report of Working Groups I and II of the Intergovernmental Panel on Climate Change. 582 p., Cambridge University Press, Cambridge, U.K. / New York, NY, U.S.A. ISBN: 978-1107607804. Disponível on-line em http://www.ipcc-wg2.gov/SREX/images/uploads/SREX-All_FI NAL.pdf.

Firestone, R.B.; West, A.; Kennett, J.P.; Beckere, L.; Bunchf, T.E.; Revayg, Z.S.; Schultzh, P.H.; Belgyag, T.; Kennetti, D.J.; Erlandsoni, J.M.; Dickensonj, O.J.; Goodyeark, A.C.; Harrish, R.S.; Howardl, G.A.; Kloostermanm, J.B.; Lechlern, P.; Mayewskio, P.A.; Montgomeryj, J.; Poredap, R.; Darrahp, T.;Que Heeq, S.S.; Smitha, A.R.; Stichr, A.; Toppings, W.; Wittkef J.H.; Wolbachr, W.S. (2007) - Evidence for an extraterrestrial impact 12,900 years ago that contributed to the megafaunal extinctions and the Younger Dryas cooling. PNAS Proceedings of the National Academy of Sciences of the United States of America, 104(41):16016-16021. DOI: 10.1073/pnas. 0706977104.

Foucault, M. (1992) - Primeira Leccion 7 de enero de 1976 Erudición y saberes sometidos. (15-32) In: Genealogía del Racismo - De la guerra de las razas al racismo de Estado, Madrid, Espanha, La Piqueta. ISBN: 8477311307.

Fukuyama, F. (1999) - Social Capital and Civil Society. Prepared for delivery at the IMF Conference on Second Generation Reforms, The Institute of Public Policy, George Mason University, U.S.A. Disponível on-line em https://www.imf.org/ external/pubs/ft/seminar/1999/reforms/fukuyama.htm - I.

Ganopolski, A.; Rahmstorf, S. (2001) - Rapid changes of glacial climate simulated in a coupled climate model. Nature, 409:153158. DOI: $10.1038 / 35051500$.

Ghosha, P.; Ghosh, P.; Bhattacharya, S.K. (2001) - CO2 levels in the Late Palaeozoic and Mesozoic atmosphere from soil carbonate and organic matter, Satpura basin, Central Índia. Palaeogeography, Palaeoclimatology, Palaeoecology, 170(34):219-236. DOI: 10.1016/S0031-0182(01)00237-1.

Giddens, A. (1991) - As consequências da modernidade. 180 p., Editora UNESP, São Paulo, SP, Brasil. ISBN: 8571390223. Disponível on-line em http://www.afoiceeomartelo.com.br /posfsa/Autores/Giddens,\%20Anthony/ANTHONY\%20GIDDE NS\%20-\%20As\%20Consequencias\%20da\%20Modernidade.pdf

Glikson, A.Y. (2014) - Early Atmosphere-Ocean-Biosphere Systems. In: Andrew Y. Glikson, Evolution of the Atmosphere, Fire and the Anthropocene Climate Event Horizon, pp. 3-19, Springer Netherlands. ISBN: 978-9400773318. DOI: 10.1007/ 978-94-007-7332-5_1.

Guerra, I.C. (2006) - Pesquisa Qualitativa e Análise de ConteúdoSentidos e formas de uso. Principia, Cascais, Portugal. ISBN: 978-9728818661. 
Guo, Q.; Strauss, H.; Kaufman, A.J.; Schröder, S.; Gutzmer, J. (2009) - Reconstructing Earth's surface oxidation across the Archean-Proterozoic transition. Geology, 37(5):399-402. DOI: 10.1130/G25423A.1.

Hettinger, N. (2005) - Desobediência ambiental. In: D. Jamieson (coord.), Manual de Filosofia do Ambiente, pp. 509-520, Instituto Piaget, Lisboa, Portugal. ISBN: 978-9727717729.

Higgins, S.S. (2005) - Fundamentos Teóricos do Capital Social. 263 p., Unochapecó, Argos Editora, Chapecó, Brasil. ISBN: 8598981176.

Houde, N. (2007) - The six faces of traditional ecological knowledge: challenges and opportunities for Canadian co-management arrangements. Ecology and Society (ISSN: 1708-3087), 12(2):art 34, Acadia University, Wolfville, Nova Scotia, Canada. Disponível on-line em http://www.ecologyand society.org/vol12/iss2/art34/.

Houghton, J.T.; Meira Filho, L.G.; Callander B.A.; Harris N.; Kattenberg, A.; Maskell, K. (eds.) (1996) - The Science of Climate Change. Contribution of Working Group I to the Second Assessment Report of the Intergovernmental Panel on Climate Change. 567 p., Cambridge University Press, Cambridge, U.K. / New York, NY, U.S.A. ISBN: 9780521564366. Disponível on-line em https://www.ipcc.ch/ ipccreports/sar/wg_I/ipcc_sar_wg_I_full_report.pdf.

IPCC (2007) - Climate Change 2007: Synthesis Report. 104 p. IPCC, Geneva, Switzerland. ISBN: 9291691224. Disponível on-line em http://www.ipcc.ch/publications_and_data/publica tions_ipcc_fourth_assessment_report_synthesis_report.htm.

Ishihara, H.; Pascual, U. (2008) - Social capital in community level environmental governance: A critique. Ecological Economics, 68(2009):1549-1562. DOI: 10.1016/j.ecolecon.2008.11.003

Jodelet, D. (2006) - Place de l'expérience vécue dans le processus de formation des représentations sociales. In: V. Hass (ed.), Les savoirs du quotidien. Transmissions, Appropriations, Représentations, pp.235-255, Les Presses Universitaires de Rennes, Rennes, França. ISBN: 9782753503137. Disponível on-line em $\mathrm{http} / /$ classiques.uqac.ca/contemporains/jodelet_denise/place_ex perience_processus/place_experience_processus.pdf.

Johnson, R.G.; McClure, B.T. (1976) - A model for Northern Hemisphere continental ice sheet variation. Quaternary Research, 6(3):325-353. DOI: 10.1016/0033-5894(67)90001-4.

Jonas, H. ([1979] 1984) - The Imperative of Responsibility: In Search of an Ethics for the Technological Age. 255 p., University of Chicago Press, Chicago, IL, USA. ISBN: 0226405966.

Jones, A.; Panagos, P.; Barcelo, S.; Bouraoui, F.; Bosco, C.; Gardi, C.; Erhard, M.; Hervás, J.; Hiederer, R.; Jeffery, S.; Lükewille, A.; Marmo, L.; Montanarella, L.; Olazábal, C.; Petersen, J.E.; Penizek, V.; Strassburger, T; Tóth, G.; Eeckhaut, M.V.D.; Liederkerke, M.V.; Verheijen, F.; Viestova, E.; Yigini, Y. (2012) - The State of Soil in Europe. A Contribution of the JRC to the European Environment Agency's Environment State and Outlook Report. 76p., Publications Office of the European Union, Luxemburg. ISBN: 978-9279228063. Disponível on-line em http://ec.europa.eu/dgs/jrc/downloads/jrc_reference_report 201202 soil.pdf

Kuhlbrodt, T.; Griesel, A.; Montoya, M.; Levermann, A.; Hofmann, M.; Rahmstorf, S. (2007) - On the driving processes of the Atlantic meridional overturning circulation. Reviews of Geophysics, 45(2): 32p. DOI: 10.1029/2004RG000166.

Lahire, B. (2005) - Patrimónios Individuais e Disposições. Para uma Sociologia à Escala Individual. Revista Sociologia, Problemas e Práticas (ISSN: 0873-6529), 49:11-42, CIESCentro de Investigação e Estudos de Sociologia, Lisboa, Portugal. Disponível on-line em http://www.scielo.gpeari.mctes. $\mathrm{pt} / \mathrm{pdf} / \mathrm{spp} / \mathrm{n} 49 / \mathrm{n} 49 \mathrm{a} 02$.pdf.
Le Treut, H.; Somerville, R.; Cubasch, U.; Ding, Y.; Mauritzen, C.; Mokssit, A.; Peterson, T.; Prather, M. (2007) - Historical Overview of Climate Change Science. In: S. Solomon, D. Qin, M. Manning, Z. Chen, M. Marquis, K.B. Averyt, M. Tignor \& H.L. Miller (eds.), Climate Change 2007: The Physical Science Basis. Contribution of Working Group I to the Fourth Assessment Report of the Intergovernmental Panel on Climate Change, pp.93-127, Cambridge University Press, Cambridge, U.K. / New York, NY, U.S.A. Disponível on-line em https://www.ipcc.ch/pdf/assessment-report/ar4/wg1/ar4-wg1chapter1.pdf.

Lidskog, R. (2008) - Scientised citizens and democratised science. Re-assessing the expert-lay divide. Journal of Risk Research, 11(1-2):69-86. DOI: 10.1080/13669870701521636

Lourenço, O.M. (2002) - Desenvolvimento Sócio-Moral. 238 p., Universidade Aberta, Lisboa, Portugal. ISBN: 9789726743736.

Lyons, T.W.; Reinhard, C.T.; Planavsky, N.J. (2014) - The rise of oxygen in Earth's early ocean and atmosphere. Nature, 506:307-315. DOI: 10.1038/nature13068.

MA- Millennium Ecosystem Assessment (2003) - Ecosystems and Human Well-being: A Framework for Assessment. 266p., Island Press, Washington, DC, USA. ISBN: 1559634030. Disponível on-line em http://pdf.wri.org/ecosystems_human_wellbeing.pdf.

MA- Millennium Ecosystem Assessment (2005) - Ecosystems and Human Well-being: Synthesis. 155 p., Island Press, Washington, DC, USA. ISBN: 1597260401. Disponível on-line em http://www.unep.org/maweb/documents/document.356.aspx.pdf

Marshall, C.R. (2006) - Explaining the Cambrian "explosion" of animals. Annual Review of Earth and Planetary Sciences, 34:355-384. DOI: 10.1146/annurev.earth.33.031504.103001.

Maruyamab, S.; Sawakia, Y.; Ebisuzakic, T.; Ikomad, M.; Omorie, S.; Komabayashia, T. (2014) - Initiation of leaking Earth: An ultimate trigger of the Cambrian explosion. Gondwana Research, 25(3):910-944. DOI: 10.1016/j.gr.2013.03.012.

Mathews, F. (2005) - Ecologia profunda. In: D. Jamieson (coord.), Manual de Filosofia do Ambiente, 227-231, Instituto Piaget, Lisboa, Portugal. ISBN: 9789727717729.

Melott, A.L.; Thomas, B. C.; Dreschhoff, G.; Johnson, C.K. (2010) - Cometary airbursts and atmospheric chemistry: Tunguska and a candidate Younger Dryas event. Geology, 38(4):355-358. DOI: $10.1130 / \mathrm{G} 30508.1$

Monteith, D.T.; Stoddard, J.L.; Evans, C.D.; Wit, H.A.; Forsius, M.; Høgåsen, T.; Wilander, A.; Skjelkvåle, B.L.; Jeffries, D.S.; Vuorenmaa, J.; Keller, B.; Kopácek, J.; Vesely, J. (2007) Dissolved organic carbon trends resulting from changes in atmospheric deposition chemistry. Nature, 450:537-540. DOI: 10.1038 /nature 06316 .

Morbidelli, A.; Chambers, J.; Lunine, J. I.; Petit, J.M.; Robert, F.; Valsecchi, G.B.; Cyr, K.E. (2000) - Source regions and timescales for the delivery of water to the Earth. Meteoritics \& Planetary Science, 35(6):1309-1320. DOI: 10.1111/j.19455100.2000.tb01518.x

Næss, A. (1986) - The Deep Ecological Movement: Some Philosofical Aspects. Philosophical Inquiry, 8(1/2):10-31. DOI: 10.5840/philinquiry 198681/22.

Nisbet, E.G.; Sleep, N.H. (2001) - The habitat and nature of early life. Nature, 409:1083-1091. DOI: 10.1038/35059210.

Nutman, A.P., Mojzsis, S.J., Friend, C.R.L. (1997) - Recognition of $\geq 850 \mathrm{Ma}$ water-lain sediments in West Greenland and their significance for the early Archean Earth. Geochimica et Cosmochimica Acta, 61(12):2575-2484. DOI: 10.1016/S00167037(97)00097-5.

Paiva, A.M. (2008) - Estrela Sociológica: Um modelo viável para o capital social. 508p., Tese de Doutoramento, Universidade 
Aberta, Lisboa, Portugal. Disponível on-line em https:// repositorioaberto.uab.pt/handle/10400.2/1435.

Paton, K.; Fairbairn-Dunlop, P. (2010) - Listening to local voices: Tuvaluans respond to climate change. Local Environment, 15(7):687-698. DOI: 10.1080/13549839.2010.498809.

Pickett, S.T.A.; Ostefeld, R.S. (1995) - The shifting paradigm in ecology. In: R.L. Knight; S.F. Bates, (Eds.), A new century for natural resources management, 262-295, Island Press, Washington, DC, USA. ISBN: 1559632615.

Pinti, D.L. (2005) - The Origin and Evolution of the Oceans. In: M. Gargaud, B. Barbier, H. Martin \& J. Reisse (eds.), Lectures in Astrobiology, 1:83-112, Springer-Verlag, Berlin / Heidelberg, Germany. ISBN: 978-3540262299. DOI: 10.1007/10913406_4.

Plano Nacional de Acção para as Energias Renováveis (s/d) - Plano Nacional de Acção para as Energias Renováveis ao Abrigo da Directiva 2009/28/CE. (De acordo com o modelo estabelecido pela Decisão da Comissão de 30.6.2009). 144p ., Disponível online em http://www.ebb-eu.org/legis/ActionPlanDirective2009 _28/national_renewable_energy_action_plan_portugal_pt.pdf.

Putman, R.D. (1995) - Tuning In, Tuning Out: the strange disappearance of social capital. America. Political Science and Politics, 28(04):664-683. DOI: 10.2307/420517.

Ramanathan, V.; Crutzen, P.J.; Kiehl, J.T.; Rosenfeld D. (2001) Aerosols, Climate, and the Hydrological Cycle. Science Review, 294(5549):2119-2124 DOI: 10.1007/10913406_4

Rosing, M.T.; Rose, N.M.; Bridgwater, D.; Thomsen, H.S. (1996) Earliest part of Earth's stratigraphic record: A reappraisal of the $>3.7 \mathrm{Ga}$ Isua (Greenland) supracrustal sequence. Geology, 24(1):43-46. DOI: 10.1130/0091-7613(1996)024<0043: EPOESS $>2.3 . \mathrm{CO} ; 2$.

Rothschild, L.J.; Mancinelli, R.L. (2001) - Life in extreme environments. Nature, 409:1092-1101. DOI: 10.1038/35059215.

Santos, B.S. (1999) - Um Discurso sobre as Ciências. 62 p., Edições Afrontamento, Porto, Portugal. ISBN: 9789723601749.

Santos, B.S. (2005) - The Future of the World Social Forum: The work of Translation. Development, 48(2):15-22. DOI: 10.1057/palgrave.development.1100131.

Santos, B.S.; Meneses, M.P.G.; Nunes, J.A. (2004) - Introdução: para ampliar o cânone da ciência: a diversidade epistemológica do mundo. In: B.S. Santos (org.), Semear outras Soluções - Os Caminhos da Biodiversidade e dos Conhecimentos Rivais, pp.19-101, Edições Afrontamento, Porto, Portugal. ISBN: 9789723607208.

Schidlowski, M. (1988) - A 3,800-million-year isotopic record of life from carbon in sedimentary rocks. Nature, 333:313-318. DOI: $10.1038 / 333313 \mathrm{a} 0$.

Schopf, J.W. (2006) - Fossil evidence of Archaean life. Philosophical Transactions of the Royal Society B (Biological Sciences), 361(1470):869-885. DOI: 10.1098/rstb.2006.1834

Schopf, J.W.; Kudryavtsev, A.B.; Czaja, A.D., Tripathi, A.B. (2007) - Evidence of Archean life: Stromatolites and microfossils. Precambrian Research, 158(3-4):141-155. DOI: 10.1016/ j.precamres.2007.04.009.

Sellers, P.J.; Dickinson, R.E.; Randall, D.A.; Betts, A.K.; Hall, F.G.; Berry, J.A.; Collatz, G.J.; Denning, A.S.; Mooney, H.A.; Nobre, C.A.; Sato, N.; Field, C.B.; Henderson-Sellers, A. (1997) Modeling the Exchanges of Energy, Water, and Carbon Between Continents and the Atmosphere. Science, 275(5299): 502-509. DOI: 10.1126/science.275.5299.502.

Shields-Zhou, G.; Och, L. (2010) - The case for a Neoproterozoic Oxygenation Event: Geochemical evidence and biological consequences. GSA Today, 21(3):4-11. DOI: 10.1130/ GSATG102A.1.
Shrader-Frechette, K. (2005) - Ecologia. In: D. Jamieson (coord.), Manual de Filosofia do Ambiente, 313-324, Instituto Piaget, Lisboa, Portugal. ISBN: 978-9727717729.

Shue, H. (2005) - Clima. In: D. Jamieson (coord.), Manual de Filosofia do Ambiente, 459-469, Instituto Piaget, Lisboa, Portugal. ISBN: 978-9727717729.

Silva, L.F.; Alves, F. (2011) - Compreender as racionalidades leigas sobre saúde e doença. Physis Revista de Saúde Coletiva (ISSN: 0103-7331), 21(4):1207-1229, Institute of Social Medicine, Rio de Janeiro State University (IMS-UERJ), Rio de Janeiro, RJ, Brasil. Disponível on-line em http://www.scielo.br/pdf/physis/ v2 $1 \mathrm{n} 4 / \mathrm{a} 02 \mathrm{v} 21 \mathrm{n} 4$.pdf.

Stocker, T.F.; Qin, D.; Plattner, G.-K.; Tignor, M.; Allen, S.K.; Boschung, J.; Nauels, A.; Xia, Y.; Bex, V.; Midgley, P.M. (eds.) (2013) - Climate Change 2013: The Physical Science Basis. Summary for Policymakers. Contribution of Working Group I to the Fifth Assessment Report of the Intergovernmental Panel on Climate Change. 27 p., Cambridge University Press, Cambridge, U.K. / New York, NY, U.S.A. Disponível on-line em http://www.ipcc.ch/report/ar5/wg1/docs/WGIAR5_SPM_brochu re en.pdf.

UN-DESA (1992) - Rio Declaration on Environment and Development, Report of the United Nations Conference on Environment and Development. Annex I. A/CONF.151/26 (Vol. I) Disponível on-line em http://www.un.org/documents/ ga/conf151/aconf15126-1annex1.htm.

UN-DESA (2012) - Back to Our Common Future- Sustainable Development in the 21st century (SD21) Project-Summary for policymakers. 44 p., Disponível on-line em http://sustainable development.un.org/content/documents/UN-DESA_Back_Com mon_Future_En.pdf.

UN-FCCC (1998) - Kyoto Protocol to the United Nations Framework Convention on Climate Change. 21 p. Disponível on-line em http://unfccc.int/resource/docs/convkp/kpeng.pdf.

Ward, P.; Labandeira, C.; Laurin, M.; Berner, R.A. (2006) Confirmation of Romer's Gap as a low oxygen interval constraining the timing of initial arthropod and vertebrate terrestrialization. PNAS - Proceedings of the National Academy of Sciences of the United States of America, 103(45):1681816822. DOI: 10.1073/pnas.0607824103.

Watanabe, Y.; Martini, J.E.J.; Ohmoto, H. (2000) - Geochemical evidence for terrestrial ecosystems 2.6 billion years ago. Nature, 408:574-578. DOI: 10.1038/35046052.

Weber, M. (2014) - Conceitos Sociológicos Fundamentais, 88p, Edições 70, Lisboa, Portugal. ISBN: 9789724415598

\section{Legislação}

Despacho n. ${ }^{\circ}$ 15296/2010 de 11 de outubro [Aprova a constituição de um grupo de trabalho (GT fast start) com vista à execução da Iniciativa Portuguesa de Implementação Imediata em Matéria de Alterações Climáticas no período de 2010-2012; aprova ainda o Regulamento da Iniciativa Portuguesa de Implementação Imediata em Matéria de Alterações Climáticas]. Diário da República (ISSN: 0870-9963) $2^{\mathrm{a}}$ série, N. ${ }^{\mathrm{o}}$ 197, pp. 50183-50184, Lisboa, Portugal. Disponível on-line em http://dre.pt/pdf2sdip/2010/10/197000000/5018350185.pdf

Resolução do Conselho de Ministros n. ${ }^{\circ}$ 119/2004 [Aprova o Programa Nacional para as Alterações Climáticas - PNAC]. Diário da República (ISSN: 0870-9963), $1^{\text {a }}$ série B, N. ${ }^{\circ} 179$, pp. 4978-4994, Lisboa, Portugal. Disponível on-line em http://www.dre.pt/pdf1sdip/2004/07/179B00/49784994.PDF

Resolução do Conselho de Ministros n. ${ }^{\circ}$ 104/2006 [Aprova a actualização do Programa Nacional para as Alterações Climáticas]. Diário da República (ISSN: 0870-9963), 1ª série, 
N. ${ }^{\circ} 162$, pp. 6042-6056, Lisboa, Portugal. Disponível on-line em http://dre.pt/pdf1s/2006/08/16200/60426056.pdf

Resolução do Conselho de Ministros n. ${ }^{\circ}$ 24/2010 [Aprova a Estratégia Nacional de Adaptação às Alterações Climáticas]. Diário da República (ISSN: 0870-9963) 1 a $^{\mathrm{a}}$ série, N. ${ }^{\circ}$ 64, pp. 1090-1106, Lisboa, Portugal. Disponível on-line em http://dre.pt/pdf1sdip/2010/04/06400/0109001106.pdf

Resolução do Conselho de Ministros n. ${ }^{\circ}$ 93/2010 [Formaliza o início dos trabalhos para o desenvolvimento de instrumentos importantes da política das alterações climáticas: o Roteiro Nacional de Baixo Carbono 2020 (RNBC 2020), os respectivos planos sectoriais de baixo carbono para cada ministério e o Programa Nacional para as Alterações Climáticas para o período 2013-2020 (PNAC 2020)]. Diário da República (ISSN: 0870-9963) $1^{\text {a }}$ série, N. ${ }^{\circ} 230$, pp. 5349-5350, Lisboa, Portugal. Disponível on-line em http://dre.pt/pdf1sdip/2010/11/23000/ 0534905351.pdf 